\title{
Hydrophobic and Hydrophilic Effects in a Mussel- Inspired Citrate-Based Adhesive
}

Yiwen Xu, Yali Ji, ${ }^{*}$ Jinghong Ma ${ }^{*}$

State Key Laboratory for Modification of Chemical Fibers and Polymer Materials, College of

Material Science and Engineering, Donghua University, Shanghai 201620, China

*Corresponding authors: jiyali@dhu.edu.cn (Y. Ji), mjh68@dhu.edu.cn (J. Ma). 

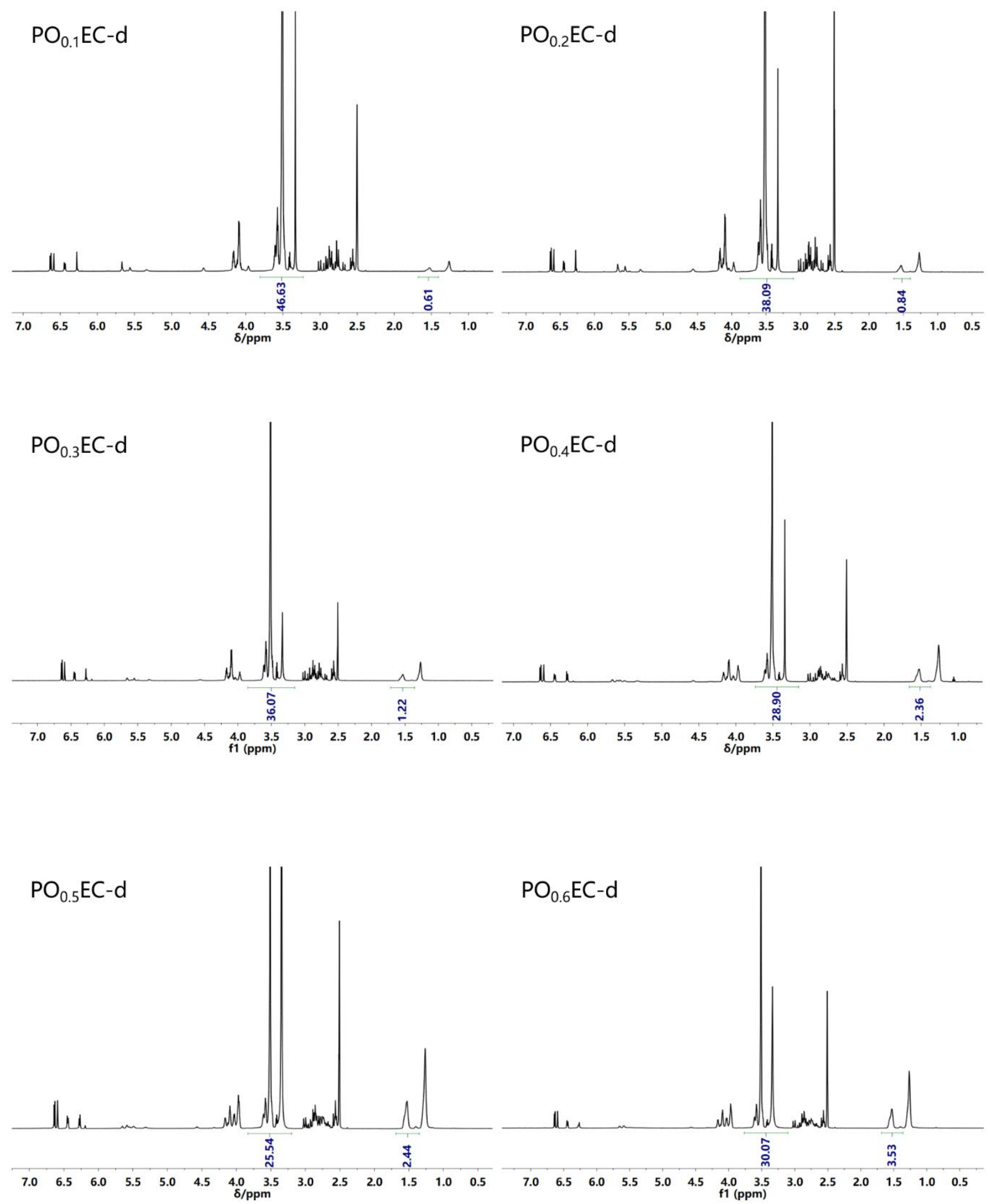

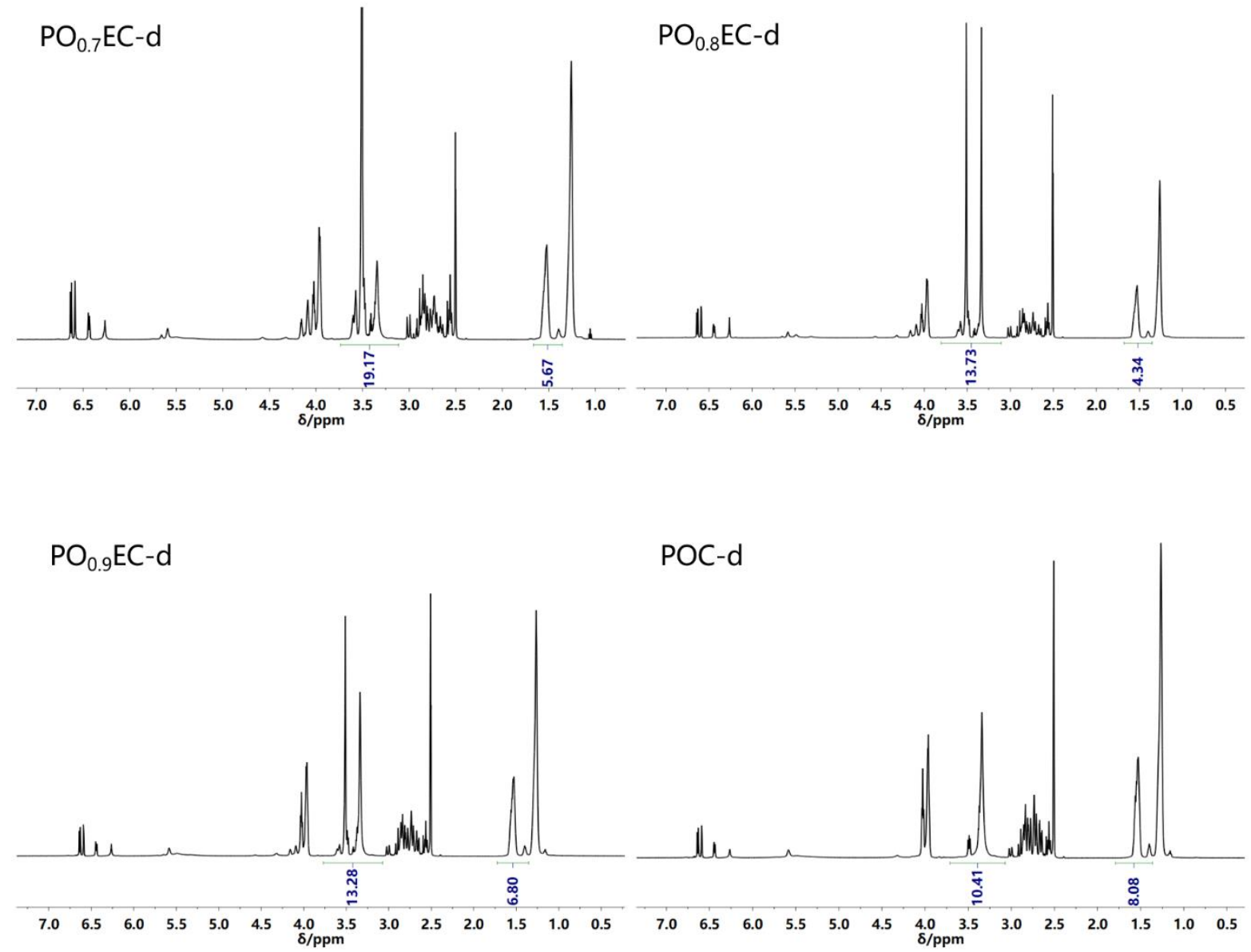

Figure S1. ${ }^{1} \mathrm{H}$ NMR spectrum of $\mathrm{PO}_{\mathrm{n}} \mathrm{EC}-\mathrm{d}$ and POC-d.

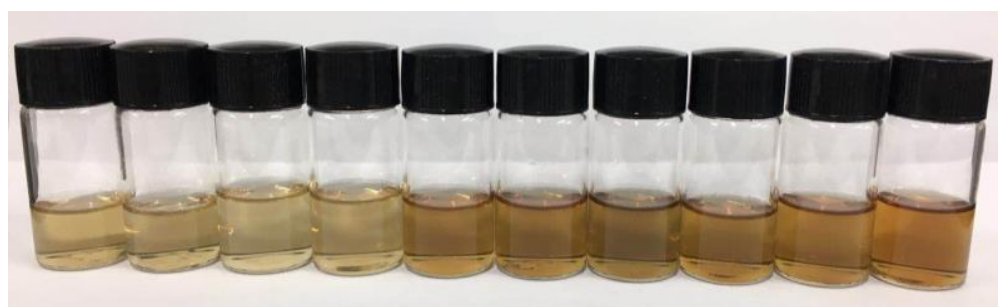

Figure S2. Images of $\mathrm{PO}_{\mathrm{n}} \mathrm{EC}-\mathrm{d}$ and POC-d adhesives solution (from left to right: POC-d, $\mathrm{PO}_{0.9} \mathrm{EC}-\mathrm{d}$ to $\left.\mathrm{PO}_{0.1} \mathrm{EC}-\mathrm{d}\right)$. 

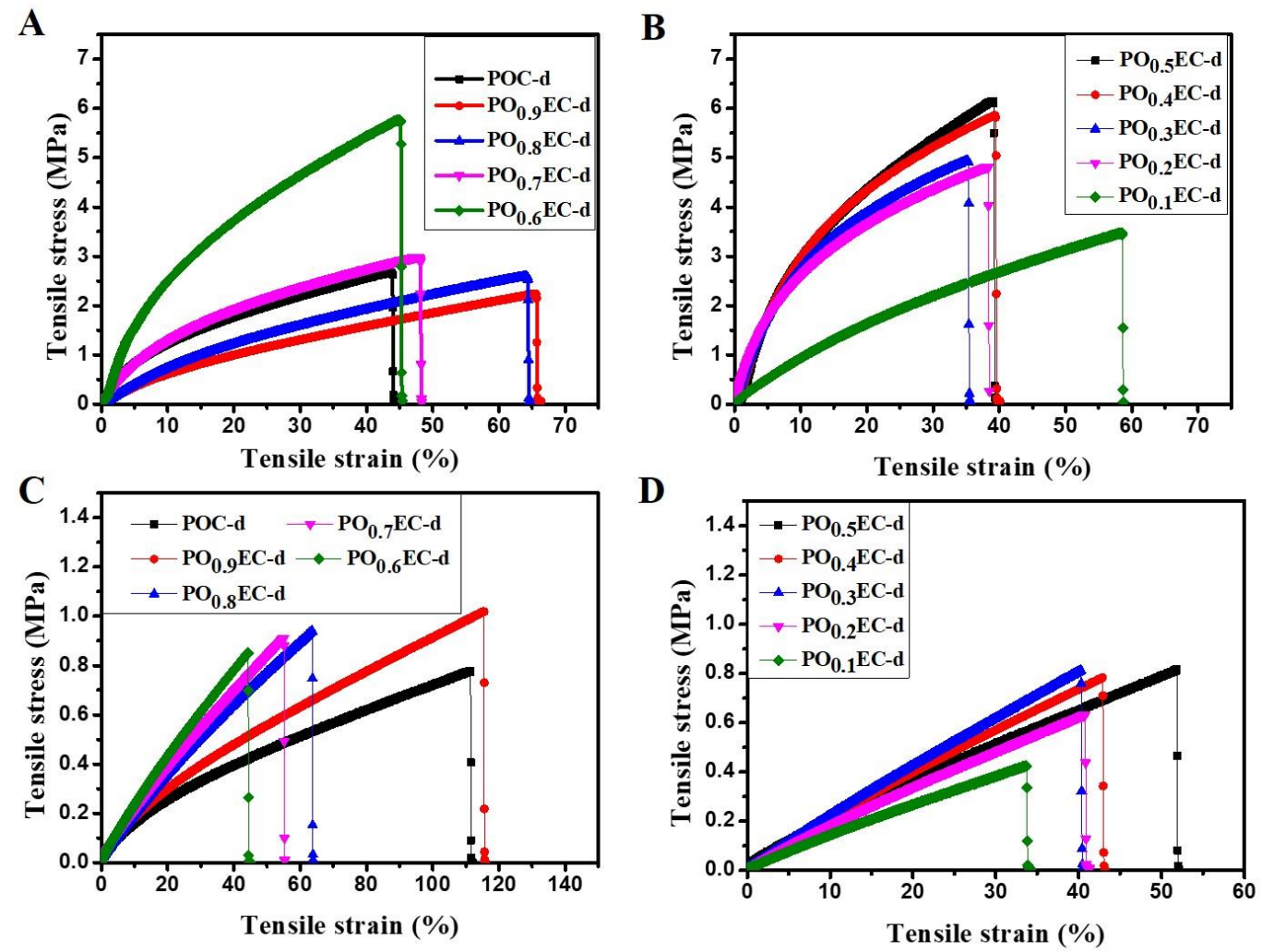

Figure S3. Stress-strain curves of cured adhesives in $\operatorname{dry}(\mathrm{A}, \mathrm{B})$ and wet (C, D) conditions. 